\title{
Do gradualismo negro ao Sonho Americano: a formação do conservadorismo negro nos Estados Unidos
}

\author{
Flávio Thales Ribeiro Francisco ${ }^{1}$
}

\begin{abstract}
Resumo: O objetivo deste artigo é analisar a linhagem histórica de conservadores negros na cultura política estadunidense. Devido ao protagonismo de lideranças progressistas no ativismo negro, reforçado pelos Movimentos pelos Direitos Civis na década de 1960, os conservadores afro-estadunidenses ocupam um espaço secundário no debate racial nos Estados Unidos. Contudo, os intelectuais negros cumpriram um papel importante nas dinâmicas políticas do país ao contribuírem com as correntes conservadoras mobilizadas a partir da década de 1950. Nesse sentido, George Schuyler, jornalista e literato negro, emerge como uma figura fundamental para a compreensão do conservadorismo negro nos Estados Unidos. A partir da sua trajetória intelectual é possível compreendermos os princípios que fundamentaram historicamente as agendas da intelectualidade negra conservadora $\mathrm{e}$ as mudanças históricas no campo conservador. Além de Schuyler, trataremos de figuras como Booker T. Washington e Thomas Sowell a fim de contextualizarmos o conservadorismo negro de maneira ampla.
\end{abstract}

Palavras-chaves: Conservadorismo negro; Sonho Americano; Identidade Negra; Movimento Negro

\section{From gradualism to American Dream: the formation of Black conservatism in United States}

\begin{abstract}
The aim of this article is to analize the historical lineage of Black conservatives in the American politics. Due to the leading role of liberal Black leadership, promoted by the Civil Right's struggle, the African-American conservatives have been overshadowed in the public debate. However, the Black conservatives played a major role in the American politics as well, contributing to the mobilization of different trends of the conservative field in the 1950's. Thus, George Schuyler, journalist and writer, emerged as a key voice in the Black activism and has been a very important intellectual for the understanding of the principles that historically pemeated the political agenda of the Black conservatives and historical changes in the conservative field. Besides Schuyler, we will also approach the experiences of Booker T. Washington and Thomas Sowell in order to give a big picture of the Black conservatism.
\end{abstract}

Keywords: Black conservatism; American Dream; Black identity; Black Movement

\footnotetext{
1 Professor dos Bacharelados de Ciências Humanas e Relações Internacionais da UFABC em São Bernardo/SP. E-mail: flavio.thales@ufabc.edu.br.
} 
Artigo recebido em: $31 / 08 / 2018$

Artigo aprovado para publicação em: 22/01/2019

A ascensão de Barack Obama nos Estados Unidos foi acompanhada pela articulação do movimento político Tea Party. Apesar da euforia de setores progressistas com a ascensão de uma ordem social multicultural nos Estados Unidos, o campo conservador emergiu como uma força que impulsionou a oposição republicana durante a presidência do democrata a partir de agendas tais quais a da política fiscal conservadora e difusão de valores individualistas. Os ativistas do Tea Party, orientados em torno de discursos libertarianistas, criticaram efusivamente o plano de resgate econômico com os recursos públicos após a crise de 2008 e a reforma da saúde proposta por Barack Obama. Entretanto, a agenda do movimento logo passou a flertar com posições racistas, sobretudo quando lideranças emitiram publicamente mensagens que associavam a "expansão" do Estado a minorias étnicas que não haviam assimilado adequadamente a ética do trabalho, qualidade reservada à maioria branca da sociedade estadunidense.

À medida em que se acentuavam os antagonismos entre republicanos e democratas, a questão racial foi ganhando cada vez mais força, obrigando o presidente, que durante a eleição evitou o tema, a se manifestar sobre episódios de racismo. A eleição de Obama, portanto, não iniciou um processo de formação de uma sociedade pós-racial, apenas recontextualizou a supremacia branca que se revelou em novos termos. A administração do presidente negro, principalmente no segundo mandato, foi acompanhada pela mobilização do movimento Black Lives Matter e a ascensão do Alt-right. O primeiro expressou a decepção de setores da população negra com a posição moderada de Obama frente aos casos de assassinatos de jovens negros por agentes de segurança, enquanto que o segundo galvanizou setores da população branca com a retórica de perda de poder de homens brancos a partir da ascensão de um presidente negro.

A insatisfação da população branca foi explorada sistematicamente pela campanha de Donald Trump que não se preocupou em disfarçar o seu discurso explicitamente racista em vários momentos. $\mathrm{O}$ atual presidente dos Estados Unidos foi bem-sucedido em explorar o 
campo conservador que se organizava durante a administração Barack Obama, porém, as duas últimas primárias republicanas foram marcadas pela competição de conservadores de diferentes matizes. Ben Carlson, atual membro da administração Trump, se revelou um competidor à altura, expressando o seu conservadorismo por meio de discursos incendiários contra os muçulmanos. Carlson, contudo, ganhou certo destaque pelo fato de ser afro-estadunidense, já que entre os negros a adesão ao Partido Republicano é muito pequena. A partir do capital propiciado pela sua trajetória profissional como cirurgião, Ben Carson ascendeu no Partido Republicano e se posicionou como uma figura exemplar a ser seguida por jovens afroestadunidenses que debatiam demasiadamente as questões raciais e não se dedicavam, segundo sua opinião, de maneira adequada aos estudos e ao trabalho.

O Movimento pelos Direitos Civis ajudou a construir um imaginário no qual o ativismo negro foi associado às posições progressistas do espectro político estadunidense. Nesse sentido, o ápice do ativismo afro-estadunidense, com atuação de figuras como Ella Baker, Martin Luther King Jr., Malcom X e Stockley Carmichael, acabou ofuscando uma linhagem histórica de conservadores negros. Ben Carlson não é uma figura fora da curva, mas parte de uma longa tradição conservadora cujas origens datam do século XIX. Enquanto a militância negra de posição progressista repudiava as práticas segregacionistas das hierarquias raciais da sociedade estadunidense, os conservadores negros definiam a assimilação de valores considerados "essencialmente americanos" como a livre iniciativa, o individualismo, o trabalho duro e o empreendedorismo como o caminho adequado para inclusão social, sem a necessidade de se engajar em confrontos violentos.

O objetivo deste artigo é compreender a formação dessa linhagem conservadora negra a partir de uma perspectiva histórica. Nesse sentido, daremos aqui destaque ao jornalista George Schuyler (1966), cuja autobiografia marcou sua posição como negro conservador. Sua trajetória é importante por ter passado pela rearticulação do campo conservador na década de 1950, marcando um divisor de águas no campo do conservadorismo e da esfera pública negra. Como acompanharemos mais adiante, esse é o momento de mobilização conservadora nos quadros do Partido Republicano e de mudanças sociais no sul do país, região onde a agenda conservadora negra teve grande adesão. 
$\mathrm{Na}$ primeira seção, trataremos brevemente da trajetória de George Schuyler, um percurso que se inicia na esquerda e se encerra com o flerte com a extrema direita estadunidense. Já na segunda seção, analisaremos os autores que discutem o conservadorismo estadunidense e o conservadorismo negro para compreendermos a constituição de uma linhagem histórica de intelectuais e lideranças negras conservadoras. Na terceira seção, voltamos à trajetória de George Schuyler para situá-lo na linhagem de conservadores negros, enquanto que na última passamos pelo debate contemporâneo para tratar da ascensão de uma nova geração de conservadores no período do pós-direitos civis.

\section{A trajetória de George Schuyler}

George Schuyler nasceu em 1895, na cidade de Providence, no estado de Rhode Island, mas viveu sua infância em Syracuse, no estado de Nova Iorque. Schuyler foi criado por sua mãe, Eliza Schuyler e sua avó, Helen Fisher, sendo que não chegou a conhecer seu pai. O historiador Oscar Williams levantou algumas questões sobre o nascimento de George Schuyler, gerando algumas controvérsias (WILLIAMS, 2007). Não há registros do nascimento de Schuyler e, no censo de 1900, Eliza Schuyler aparece como uma viúva sem filhos. A hipótese levantada é a de que o intelectual conservador foi adotado e, ao fazer considerações sobre a sua infância em sua autobiografia (SCHUYLER, 1966), procurou apagar alguns detalhes da sua história de vida que pudessem comprometer a sua narrativa biográfica.

A mãe e a avó de Schuyler eram trabalhadoras domésticas, mas ostentavam um certo prestígio em relação aos demais trabalhadores negros da cidade de Syracuse, com ocupações supostamente bem remuneradas no mercado de trabalho disponível para os negros. Em seus relatos, o intelectual conservador faz um retrato nostálgico de uma infância sem marcas do racismo e de convivência pacífica com vários grupos de imigrantes na cidade. A sua família manifestava uma rejeição à grande maioria da população negra de Syracuse, principalmente os migrantes oriundos do Sul do país, considerados inadequados e grosseiros por não ostentarem uma respeitabilidade negra. Sendo assim, os Schuylers privilegiaram o contato com os vizinhos brancos (IBIDEM, P. 11). 
A distinção da família de George Schuyler foi reforçada com uma ascendência de negros livres desde o período da independência dos Estados Unidos. No lado materno, a bisavó de George Schuyler veio de Madagascar como "trabalhadora forçada", não escrava, e serviu uma família em Nova Jersey, onde se casou com um marujo belga. No lado paterno, o bisavô de George Schuyler, que herdou o nome de seu senhor de origem holandesa, ganhou sua liberdade ao participar da luta pela emancipação das 13 colônias britânicas que dariam origem aos Estados Unidos. A possibilidade de organização de uma árvore genealógica sem a experiência da escravidão durante o século XIX permitiu que George Schuyler e seus familiares reforçassem uma superioridade baseada em um longo período de liberdade no contexto de uma nação escravocrata.

Apesar das particularidades da sua família, George Schuyler não vislumbrou em Syracuse qualquer oportunidade atrativa de emprego, a cidade também apresentava obstáculos para a ascensão social dos trabalhadores negros, mantendo-os em ocupações restritas à esfera doméstica. A sua decisão foi de abandonar a escola ainda no ensino médio. A opção de Schuyler, assim, foi comum à de outros homens negros do período: o ingresso no exército norte-americano. Em 1912, iniciou a sua carreira militar, mas sua experiência no exército teria consequências em sua trajetória intelectual. Diferentemente da maioria das lideranças negras afro-estadunidenses, formada nas universidades, George Schuyler desenvolveu suas habilidades como escritor e jornalista na redação de uma publicação militar, cultivando seu estilo irônico e satírico.

Os seis anos de experiência no exército, apesar dos elogios de superiores, não renderam nenhum tipo de promoção. Entretanto, o exercício de leitura e escrita estimulou o seu apreço pela atividade intelectual. Após a sua experiência militar, George Schuyler se ocupou de trabalhos de baixa remuneração, retornando à Syracuse em 1919. Em 1921, tornou-se membro oficial do Partido Socialista, espaço no qual identificou a possibilidade de participar de algum debate intelectual fora do âmbito acadêmico. Em sua autobiografia, publicada em 1966, já com uma carreira consolidada como pensador conservador, Schuyler relatou que sua passagem pelo partido foi marcada pelo desencantamento com o socialismo, principalmente com o que ele entendia ser uma "ortodoxia da luta de classes". 
Contudo, George Schuyler continuou a frequentar os círculos da esquerda. Em Nova Iorque, em 1922, ele conheceu A. Philiph Randolph, eminente líder negro e socialista. Após um ano de contribuições de textos para o jornal de Randolph, Messenger, Schuyler foi convidado a escrever regularmente para o periódico, discutindo questões relacionadas à população negra. Em sua escrita, reforçou o estilo sarcástico ao tratar de figuras do ativismo afro-estadunidense como Marcus Garvey e organizações racistas como a Ku Klux Klan. O recurso do deboche para criticar o racismo nos Estados Unidos logo chamou a atenção de leitores e colegas do jornalismo da imprensa negra.

Em 1925, George Schuyler se consolidaria no jornalismo ao iniciar a sua colaboração no Pittsburgh Courier, jornal semanal de circulação local cuja ambição era de se tornar o principal periódico da imprensa negra dos Estados Unidos. Até aquele momento, o Chicago Defender era a principal publicação com uma tiragem semanal de 300 mil exemplares. Robert Vann, editor que havia reestruturado o jornal em 1910, começou a atrair os seus leitores com um discurso editorial conservador que problematizava a "vitimização negra", difundindo a importância do empreendedorismo. Ao se tornar um jornalista regular do Courier, Schuyler não somente publicou textos satíricos, mas também viajou pelo território norte-americano para realizar reportagens especiais sobre as experiências negras nos estados do sul, divulgando também o periódico. Com a contribuição de Schuyler, o Pittsburgh Courier atingiria uma tiragem de 400 mil exemplares na década de 1940 (WATSON, 2013).

A década de 1930 foi de ascensão para Schuyler na esfera pública. Nesse período, ele escreveu dois romances, Black no More e Slaves of today: a story of Liberia, ambos em 1931, nos quais tratou respectivamente dos problemas das categorias raciais e da escravidão no país africano. É também nesse momento que ele passa a manifestar de maneira clara a sua postura conservadora, quando atacou o Partido Comunista que disputava a defesa de réus negros no caso de Scottboro com a NAACP, também em 1931. Nove jovens negros foram acusados injustamente de estuprarem duas garotas brancas em um trem, Schuyler alegou que os comunistas não poderiam fazer a defesa, pois eram considerados elementos subversivos pela sociedade, o comunismo era uma ideologia desagregadora e comprometeria ainda mais a situação dos réus: 
Os comunistas nos Estados Unidos são mais uma ameaça do que uma promessa para os negros. A estratégia é a de fazer capital político através da questão racial, assim como o Bleases e o Heflins fazem no Sul. Não há interesse na situação dos indivíduos negros que são defendidos por eles. O que eles estão querendo fazer é promover atividades revolucionárias e a queda do governo. (PITTSBURGH COURIER, 18 de julho de 1931)

Ao mesmo tempo em que George Schuyler recrudescia a sua retórica conservadora, deslocava-se em jornadas nacionais e internacionais, construindo um quadro amplo de experiências negras para os leitores do Pittsburgh Courier. Schuyler realizava viagens para conduzir as reportagens especiais do periódico, dentre as quais um destino de grande importância foi para a América Latina, em 1948. O jornalista fez uma jornada pelo continente com a preocupação de testemunhar a situação das populações negras em Cuba, Panamá, Colômbia, Venezuela e Brasil, cujo principal objetivo era avaliar a participação dos negros nos exércitos. No Brasil, Schuyler visitou a cidade do Rio de Janeiro e se encontrou com ativistas do Teatro Experimental do Negro, estabelecendo um breve contato com Abdias do Nascimento. No jornal Quilombo, publicação da organização negra, foi publicada uma entrevista com Schuyler falando de suas impressões sobre o Brasil (QUILOMBO, 9 de dezembro de 1948, p. 2). Diferentemente de outros afro-estadunidenses que observaram as relações raciais no Brasil e em outros países da América Latina, o jornalista não afirmou a existência de uma harmonia racial entre negros e brancos nas sociedades latino-americanas, identificando uma pobreza negra e dificuldades para a mobilidade social. Apesar da segregação racial nos Estados Unidos, segundo Schuyler, havia brechas que possibilitavam a ascensão social de profissionais liberais e empreendedores negros.

Na década de 1950, Schuyler manifestou a sua euforia em torno do anticomunismo promovido pelo senador Joseph McCarthy nos Estados Unidos, opondo-se não somente aos comunistas, mas também às lideranças negras que ascenderiam com o Movimento pelos Direitos Civis a partir de 1954. Em tom belicista, George Schuyler criticou o que entendeu ser um oportunismo de ativistas negros como Martin Luther King Jr., "influenciados pelo comunismo" e irresponsáveis ao arrastarem cidadãos negros para um conflito violento contra os brancos do sul do país. A postura de Schuyler o afastou até mesmo de ativistas mais moderados, mas o aproximou de organizações conservadoras, tais como a John Birch Society. Em 1966, Schuyler encerrou suas atividades no Pittsburgh Courier após controvérsias sobre a sua postura 
demasiadamente conservadora. Apesar de encontrar oportunidades nos periódicos de direita com leitores interessados nos comentários de um negro que fazia oposição ao Movimento pelos Direitos Civis, o jornalista iniciou uma trajetória de declínio que decretaria o fim de sua carreira. A publicação de sua autobiografia, em 66, foi o último ato de um intelectual que procurou afirmar sua identidade como conservador (SCHUYLER, 1966).

\section{O Conservadorismo nos Estados Unidos}

O auge da carreira de George Schuyler ao longo das décadas de 1940 e 1950 acompanhou a organização de um campo conservador na política norte-americana. Esse movimento resultou de uma reação à consolidação de um Estado liberal ${ }^{2}$ com origem no New Deal, do presidente democrata Franklin D. Roosevelt. O aumento do governo federal, as regulações da relação entre patrões e empregados, o aumento da carga de impostos e os programas de auxílios sociais provocaram reações de diferentes vozes conservadoras que não se encontravam necessariamente organizadas e ocupavam ainda um lugar periférico. No quadro político daquele momento se manifestavam correntes que afirmavam a importância da tradição e o respeito às hierarquias e outras que tratavam do fardo do Estado sobre as iniciativas privadas e os indivíduos (DUNN, 1996). Já em 1935, Garet Garrett denunciava o New Deal como um ataque ao capitalismo e ao individualismo ao prover seguros sociais para uma classe de dependentes, comprometendo a iniciativa privada. No outro lado do espectro político conservador, Ralph Cram ecoava o argumento de alguns intelectuais conservadores que anunciavam o declínio da civilização ocidental partir da ascensão das democracias de massas (SCHNEIDER, 2009, p. 13).

A heterogeneidade do conservadorismo norte-americano foi um desafio para os seus estudiosos, que sempre encontraram dificuldades para definir um conceito de conservadorismo para a cultura política estadunidense. A obra Russel Kirk, The Conservative Mind (1953), foi considerada um estudo pioneiro do fenômeno (KIRK, 2001). Kirk, um estadunidense que

\footnotetext{
${ }^{2} \mathrm{O}$ termo liberal aqui se refere à versão norte-americana de socialdemocracia com a formação de um Estado forte de economia regulada. Ver LIMONCIC, Flavio. Os inventores do New Deal: Estado e sindicatos no combate à Grande Depressão. Rio de Janeiro: Civilização Brasileira, 2009; GERSTLE, Gary; FRASER, Steve (org.). The rise and fall of New Deal order (1930-1980). Princeton: Princeton University Press, 1989.
} 
desenvolveu sua pesquisa de doutorado na universidade escocesa de Saint Andrew, identificou as origens do conservadorismo estadunidense em obras de pensadores britânicos como Edmund Burke, constituindo uma genealogia conservadora anglo-americana. Os princípios conservadores que delinearam a reação de Burke à Revolução Francesa se reproduziriam em obras de outros intelectuais e estadistas estadunidenses ao longo dos anos, configurando uma tradição conservadora. Em sua obra, Russel Kirk estabelece uma relação dos princípios que definiriam um conservador como "a crença em uma ordem moral", o "respeito às convenções sociais", a "afirmação da prudência como virtude", "a ligação íntima entre liberdade e propriedade" e a "a conciliação entre permanência e mudança".

No entanto, a análise erudita e refinada de Kirk para identificar e definir um cânone do pensamento conservador não foi o suficiente para contemplar a diversidade de correntes do conservadorismo estadunidense no século XX. Apesar dos elogios, Conservative Mind gerou controvérsias, acentuadas pela ideia de conservadorismo proferida pelo autor em outros textos. O questionamento era o de que Russel Kirk havia privilegiado um conservadorismo tradicionalista circunscrito ao campo da cultura e insuficiente para tratar de outras questões caras aos conservadores da década de 1950. Frank Meyer, por exemplo, ressaltou que o problema fundamental naquele momento era o da competição entre o coletivismo/estatismo bem como entre individualidade/liberdade econômica. Para ele, o tradicionalismo de Kirk era coletivista e refutava o individualismo como base para uma sociedade, o seu tradicionalismo poderia degenerar-se em uma espécie de totalitarismo (MEYER, pp. 559-562).

Já em um período posterior, em 1976, o historiador George Nash, com um certo distanciamento temporal dos grupos conservadores que ascenderam durante a década de 1940, compreendeu o fenômeno conservador como um movimento heterogêneo que conciliaria as suas tendências a partir do anticomunismo da década de 1950 (NASH, 2006). Ao tratar do conservadorismo, Nash desenvolveu uma abordagem distinta daquela de Russel Kirk, evitando a definição de princípios conservadores e observando articulações de redes de intelectuais e políticos que configurariam um campo conservador. As vozes isoladas do conservadorismo durante os primeiros anos do New Deal se organizariam em três correntes: a primeira delas formada por liberais clássicos, ou libertarianos, que resistiam à expansão do estado e à "ameaça 
à iniciativa privada e ao individualismo". Já a segunda foi formada por tradicionalistas como Richard Weaver, Peter Viereck, Robert Nisbet e o próprio Russel Kirk. Frente à secularização de uma sociedade de massas "sem raízes", tais intelectuais propunham o retorno "das verdades religiosas" e a rejeição de um relativismo que destruía os valores ocidentais. A terceira se apresentava como uma militância anticomunista formada por ex-radicais de esquerda como Whittaker Chambers, James Burnham e Frank Meyer, articulados em uma cruzada implacável contra a ameaça global do comunismo.

No entanto, a coexistência entre essas correntes foi marcada por tensões. Na interpretação do historiador, o anticomunismo acabou funcionando como um elemento agregador de tradicionalistas e libertarianos, possibilitando a convivência entre os dois grupos. Por volta de 1960, de acordo com Nash, os ânimos foram apaziguados por meio de iniciativas para conciliálos. Frank Meyer, que havia feito fortes críticas aos tradicionalistas, criaria a teoria do fusionismo que combinaria uma ordem moral, a valorização do indivíduo e a afirmação da Constituição frente ao comunismo, incorporando princípios das três correntes. A tentativa de equilíbrio da tríade a partir do fusionismo permitiu a Nash delinear uma fronteira para o campo conservador, reforçando a formação de um movimento que emergeria com força na política.

A interpretação do historiador, apesar de não contemplar os ansiosos por uma definição rigorosa de conservadorismo, foi muito bem recebida e ainda hoje se sustenta como a narrativa de ascensão do conservadorismo nos anos 50. Estudos posteriores, como os de Gregory Schneider (2009), Laura Jane Gifford (2009) e James Brian McPherson (2008), trataram de expandir a teoria de Nash para um período histórico mais longo e outros campos específicos, como o da imprensa, considerando, por exemplo, a ascensão de Ronald Reagan em 1980 e a atuação dos conservadores nos veículos de comunicação de massa.

A partir de 1940, portanto, é possível identificar a articulação de intelectuais conservadores e de uma rede de organizações políticas que posteriormente formaria a base para a ascensão do conservadorismo no Partido Republicano. No plano intelectual, revistas como a National Review, editada por William Buckley Jr., organizaram o campo intelectual, fortalecendo a crítica ao liberalismo estadunidense (SOUSA, 2013). No plano político, Barry Goldwater, com uma agenda conservadora, chegaria até a disputa da presidência contra o democrata Lindon 
Johnson em 1964. Embora tenha sido derrotado por uma ampla margem, abriu caminho para outros políticos e ativistas conservadores no Partido Republicano, que ganharia uma nova identidade nos anos 70 .

Esse é o contexto no qual estava inserido George Schuyler. O seu conservadorismo só pode ser compreendido se levarmos em consideração a ascensão de um movimento conservador organizado em torno da oposição a uma ordem liberal construída a partir do New Deal de Franklin D. Roosevelt. Por outro lado, há uma série de elementos do conservadorismo de Schuyler que não estão presentes nesse fenômeno da política estadunidense e que só podem ser identificados em uma longa tradição do conservadorismo negro e suas particularidades.

\section{A tradição do conservadorismo estadunidense}

Diferentemente do conservadorismo emergido ao longo da década de 1950, o conservadorismo negro não se transformou em um movimento político organizado para a disputa de poder. É verdade que um grupo de intelectuais negros conservadores procurou se articular nos anos 80 - na Black Alternatives Conference - para refletir sobre um suposto esgotamento do Movimento pelos Diretos Civis, oferecendo uma alternativa conservadora para o progresso da população negra no momento da ascensão de Ronald Reagan (WRIGHT, 2009). Entretanto, esses conservadores contemporâneos, liderados por figuras como Thomas Sowell e Walter Williams, nunca foram capazes de atrair o interesse da população negra.

O conservadorismo negro também apresenta desafios para os seus estudiosos. Um dos primeiros a tentar definir o perfil de um negro conservador foi o sociólogo Kelly Miller, comparando figuras que considerava radicais, como o abolicionista Frederick Douglass, com as consideradas conservadoras, como Booker T. Washington, liderança negra que emergiu na década de 1890 (MILLER, 1968). Enquanto Douglass havia desafiado os defensores da escravidão, Booker T. Washington, de acordo com Miller, se apresentava como um líder prudente que não confrontava os opressores de frente, privilegiando assuntos econômicos sem se arriscar em uma luta pela igualdade de direitos. Portanto, Washington incorporaria a figura do líder pragmático que agia em uma margem estreita de segurança, acomodando-se ao regime de opressão sobre os negros no sul dos Estados Unidos. 
O conservadorismo negro, nesse sentido, estaria associado ao debate sobre as estratégias de confronto ao racismo. Lee Walker, por exemplo, afirma que uma das diferenças fundamentais entre conservadores e liberais negros é que os primeiros entendiam que a integração era resultado de um conjunto de iniciativas implementadas para o progresso moral e econômico dos negros, enquanto os segundos tinham a integração como prioridade (WALKER, 2009). No entanto, o conservadorismo não se resumia a um longo período de estratégias pragmáticas que resultariam na igualdade de direitos. Para Walker, que faz referência à obra de Russel Kirk, o gradualismo dos conservadores negros era orientado por um conjunto de temas e princípios como o empreendedorismo, a autodeterminação e a autossuficiência, que estavam presentes no conservadorismo do Booker T. Washington e seus seguidores.

Peter Eisenstadt (2012) e Chisthopher Bracey (2008) seguem a mesma linha, identificando princípios e valores conservadores que se revelam na cultura política afro-estadunidense. Os dois estudiosos do conservadorismo negro, contudo, desestabilizam as fronteiras entre conservadores e liberais, demonstrando que organizações e lideranças negras que geralmente são consideradas antípodas do conservadorismo negro também são orientadas por valores conservadores. $\mathrm{O}$ nacionalista negro Marcus Garvey e o precursor do Black Power, Stockley Carmichael, enfatizaram em seus discursos a importância da autossuficiência e da autodeterminação para a construção de uma autonomia econômica negra em relação à sociedade estadunidense. Ainda assim, os conservadores negros, segundos os autores, seriam aqueles que articulariam o individualismo, o respeito às instituições e a crença no capitalismo. Eisenstadt constata a existência de uma "ética protestante negra" que organiza um conjunto de princípios e valores de uma moral individualista que gera representações de uma respeitabilidade negra e disciplina os seus seguidores para o empreendedorismo, reforçando uma autonomia negra a partir do progresso econômico. Já Bracey identifica uma espécie de mitologia do excepcionalismo estadunidense nos discursos de algumas lideranças conservadoras, que acreditam que os negros podem e devem fazer parte de um "povo escolhido" com a histórica missão de salvar e redefinir a humanidade em nome da liberdade e da democracia.

Segundo os estudiosos, conservadorismo negro já se revelava nas práticas e nos discursos de pensadores negros do século XVIII e XIX, ainda no período de escravidão. Jupiter Hammon 
(1711-1806), por exemplo, foi escravo durante toda a sua vida. Mesmo assim, conseguiu publicar poemas, ensaios e sermões que tratavam de questões sociais relacionadas aos afroestadunidenses. Com um tom fortemente religioso, Hammon clamava pela prudência dos escravos e afirmava a necessidade de se respeitar os senhores. Ele não fazia a defesa da escravidão, mas entendia que o desrespeito à ordem poderia levar a um comportamento pecaminoso, comprometendo uma vida de eternidade após a morte. Para Hammon, portanto, liberdade era um privilégio, e não um direito. A melhor forma dos negros demonstrarem a desumanidade da escravidão seria ao conduzirem uma vida ordeira com ética e trabalho duro para desconstruir as representações estereotipadas, revelando a hipocrisia dos brancos. $\mathrm{O}$ conservadorismo de Jupiter Hammon se revelou na acomodação diante de uma rígida hierarquia racial, apostando em uma política de respeitabilidade para confrontar as supostas ideias de inferioridade negra.

Antes que a escravidão chegasse ao fim, outras figuras como Richard Allen (1760-1831) e James Forten (1766-1848) continuaram a difundir valores conservadores entre os negros. Allen, ex-escravo e fundador da African Methodist Episcopal Church, fundiu o discurso religioso com o materialismo, enfatizando o empreendedorismo e a independência econômica como recompensa por um trabalho duro. Em uma mesma lógica, Forten, empreendedor da construção de navios, chamou a atenção de seus seguidores para a temperança, indicando uma vida sem vícios e reforçando o patriotismo dos negros como caminho para o sucesso econômico nos Estados Unidos. Essas lideranças negras que atuaram no século XIX ajudaram a sedimentar uma tradição conservadora (BRACEY, 2008).

O conservadorismo negro, contudo, ganhou o seu contorno mais nítido com a ascensão de Booker T. Washington, já no período pós-abolição. A sua ascensão como liderança negra nacional foi simultânea à decisão da Suprema Corte sobre o caso Plessy vs. Fergunson, em 1896, que acabou institucionalizando a segregação racial nos Estados Unidos. Nascido escravo em 1856 na Virgínia, Washington testemunhou os últimos anos da escravidão. A sua trajetória foi marcada pela emergência de escolas profissionais no sul do país para atender a massa de libertos analfabetos no período da Reconstrução (1865-1877). Enquanto uma liderança formada nessas instituições, Booker T. Washington enfatizou em seu discurso a necessidade de educação 
profissional em detrimento de uma formação clássica ou universitária, argumentando que aprender a construir uma casa era mais importante que dominar o grego ou o latim. O líder negro procurou também difundir o empreendedorismo, criando organizações como a Negro Business League para promover comerciantes no ambiente segregado do sul dos Estados Unidos.

Washington emergiu no cenário nacional com o seu discurso em Atlanta, em 1895, no qual procurou afirmar um compromisso com os brancos do sul país, afirmando que os negros trabalhariam duro para progredir economicamente, "respeitando as fronteiras da segregação" (WASHINGTON, 1995). O líder negro conquistou o apoio de político conservadores, mas foi acusado por lideranças negras do norte de aceitar o racismo. William DuBois, um crítico ferrenho de Washington, o acusou de privilegiar uma vida material, desconsiderando a prioridade da igualdade de direitos. O termo cunhado para a abordagem do líder negro do Sul foi "filosofia da acomodação". Washington entendia que existia um atraso econômico e social dos negros, eles deveriam, portanto, progredir para que pudessem almejar a igualdade. Nesse sentido, suas estratégias incorporaram princípios como a autossuficiência, autodeterminação, empreendedorismo e o respeito às instituições estadunidenses, revelando uma confiança na capacidade do capitalismo dos Estados Unidos de promover a ascensão econômica dos negros.

Booker T. Wahington foi considerado uma liderança conservadora cuja abordagem foi ultrapassada pela geração de ativistas negros que ascenderam nas primeiras décadas do século XX. Contudo, seu discurso teve um enorme impacto sobre as populações negras do sul, que encaravam a segregação racial no cotidiano. Após a sua morte, em 1915, a filosofia da acomodação continuou a ser referência para os ativistas negros, sobretudo os do sul do país. Posteriormente, conservadores como Plummer B. Young (SUGGS, 1998), importante jornalista e ativista de Virginia, continuariam a difundir em jornais de grande circulação como o Norfolk Journal and Guide o legado de Booker T. Washington que demonstraria sua força até a década de 1940.

\section{O conservadorismo de George Schuyler}

O conservadorismo de Schuyler não se restringiu ao anticomunismo que se manifestou fortemente em seus discursos a partir da década de 1950. Historiadores como Oscar Williams 
(2007) e Harry Williams Jr. (1988), que propuseram uma história biográfica de Schuyler, se debruçaram sobre a transformação do jornalista negro em um conservador anticomunista, sem dar a devida importância aos demais elementos do seu conservadorismo. Portanto, a autobiografia de George Schuyler teve uma enorme influência sobre o modo como ativistas e estudiosos o enxergaram. Schuyler construiu uma narrativa sobre si mesmo na qual o seu conservadorismo já se manifestava na juventude. A passagem pelo Partido Socialista fora apenas um "desvio" de uma trajetória marcada primeiramente pela desconfiança com relação ao comunismo e uma posterior militância anticomunista na era do Macarthismo.

No entanto, é possível identificarmos elementos da tradição conservadora negra, além do anticomunismo, nos textos escritos pelo jornalista. No discurso conservador de Schuyler se revela a importância da autossuficiência, autodeterminação, a temperança, a acomodação bookertiana, o respeito pelas instituições e a crença na capacidade do capitalismo de promover a progresso dos negros em uma sociedade marcada por uma rígida hierarquia racial. O seu repertório, nesse sentido, reforçava o excepcionalismo dos Estados Unidos ao afirmar o país como o espaço ideal, comparado às demais nações da América, para a evolução da população negra (SCHUYLER, 1966, pp. 290-309).

Dentre os elementos do conservadorismo de Schuyler podemos destacar, por exemplo, o desconforto com a ideia de uma identidade racial. Essa é uma crítica que não era comum na tradição conservadora afro-estadunidense, mas se tornaria corriqueira na geração de conservadores negros que emergiria na década de 1980. Já em 1926, o intelectual se envolveria em uma controvérsia sobre a cultura negra nos Estados Unidos. Schuyler afirmaria a inexistência de uma arte negra que só poderia ser concebida na África. Os negros estadunidenses não poderiam criar uma arte especificamente negra porque estavam inseridos em uma cultura de matriz anglo-saxônica:

Isso é muito fácil de entender se percebemos que os afro-americanos são apenas anglosaxões negros. Se os imigrantes europeus, depois de duas ou três gerações de exposição às nossas escolas, política, propaganda, cruzada moral e restaurantes não se distinguem dos americanos tradicionais (apesar da influência da imprensa de língua estrangeira), o mesmo pode ser afirmado para os Filhos de Cam que foram influenciados pelos últimos três séculos.

(SCHUYLER, 2001, pp. 13-15). 
Para Schuyler, a identidade nacional prevaleceria sobre uma identidade negra, determinando profundamente a experiência da população afro-estadunidense no país. Os Estados Unidos, nos escritos do intelectual, apareciam como uma nação excepcional e os negros faziam parte da sua história. Nesse sentido, Schuyler enfatizou sempre aspectos compartilhados por brancos e negros, procurando diluir a importância da raça por meio da celebração de uma comunidade política capaz de abrigar os dois grupos. A militância negra, na perspectiva do conservador, aparecia muitas vezes como uma articulação de negros hipócritas que promoviam a unidade racial política e ignoravam as possibilidades de cooperação econômica com os brancos. Em seus textos, portanto, surgia a ideia dos Estados Unidos enquanto um espaço de excelência do capitalismo que permitia os seus cidadãos, inclusive os negros, progredirem a partir de iniciativas individuais:

Sem dúvida, o incremento progressivo das relações inter-raciais nos Estados Unidos é o exemplo mais concreto da superioridade da civilização americana livre sobre o reacionarismo dos regimes totalitários. É à capacidade de mudança e de adaptação inerente ao sistema de iniciativa individual e autoridade descentralizada que devemos atribuir o progresso dos negros dos Estados Unidos. (SCHUYLER, 1966, p. 321)

George Schuyler mencionava recorrentemente os exemplos de progresso econômico dos negros nos Estados Unidos independentemente da luta pela igualdade de direitos. Para ele, o país era a melhor opção para uma população negra, mesmo com a opressão racial. Quando o jornalista publicou suas experiências em uma viagem pela América Latina no Pittsburgh Courier, reforçou o argumento da excepcionalidade estadunidense, retratando sociedades com as marcas de um processo intenso de miscigenação, mas com uma pobreza negra evidente e uma falta de representatividade nas instituições de exercício do poder. Schuyler, nesse sentido, rompeu com a tendência de viajantes e intelectuais afro-estadunidenses de enxergarem na América Latina, principalmente no Brasil, paraísos raciais (HELLWIG, 1992).

A posição do negro no Brasil é economicamente e socialmente inferior ao dos negros nos Estados Unidos. As pessoas no país ficaram surpresas ao tomarem conhecimento de que eu havia viajado de avião e de que muitos afro-americanos têm condições de fazer o mesmo. Eles não conseguem imaginar um negro dirigindo um Cadillac, este 
modelo custa uma fortuna no Rio de Janeiro. A maioria dos negros foi relegada às ocupações de baixa remuneração. (SCHUYLER, 1966, p. 309).

A partir do retrato da situação “inferior” dos negros nos países da América Latina, do debate sobre a cultura negra ou dos indícios do progresso econômico dos negros, George Schuyler revelou outros aspectos do seu conservadorismo. Se por um lado o intelectual vociferava contra uma "ameaça comunista" ou lideranças negras "hipócritas" como Martin Luther King Jr., que "arriscava" o futuro dos negros da nação em um conflito racial contra os brancos, por outro demonstrava a importância do gradualismo na luta pela igualdade de direitos, indicava alternativas para o progresso econômico e destacava a importância das instituições. Schuyler atuou sob o guarda-chuva do anticomunismo que acolheu correntes ideológicas conservadoras divergentes, em 1950, e também reproduziu princípios de uma tradição conservadora negra em seus escritos.

\section{A virada no Conservadorismo negro}

Durante muito tempo o conservadorismo nos Estados Unidos teve grande difusão entre os negros nos estados do Sul. A filosofia da acomodação, advogada por Booker T. Washington, orientou sobretudo as práticas políticas de setores das elites negras, que privilegiaram a construção de redes empreendedoras como uma maneira de superar os limites impostos pelas leis segregacionistas. As figuras que defendiam as agendas inclusivas e confrontavam as barreiras raciais atuavam em estados em que a segregação não estava presente, sem serem obrigadas a encarar o repertório violento das práticas violentas racistas. A abordagem bookertiana perdeu espaço no sul a partir da ascensão do Movimento pelos Direitos Civis, que impulsionou movimentos populares na região dando início ao processo de desmantelamento da segregação racial. A partir de lideranças como Ella Baker e Martin Luther King Jr., que mobilizavam os negros em torno de um repertório não violento, emergiu no sul do país um grupo de pressão com repercução nacional e obrigou as autoridades federais a se articularem para intervir na violência racial.

Durante o processo de ascensão do Movimento pelos Direitos Civis, como observamos anteriormente, George Schuyler começou a atuar no campo conservador, contribuindo com 
figuras que seriam responsáveis pela mobilização de uma rede conservadora que tomaria o Partido Republicano na década de 1960. Assim, a trajetória de Schuyler pode ser considerada como uma antecipação da atuação dos conservadores negros após as vitórias do ativismo negro progressista. Booker T Washington tinha uma ligação orgânica com as lideranças negras do sul dos Estados Unidos, influenciando as dinâmicas políticas e econômicas de várias comunidades negras da região. Já George Schuyler acabou se isolando da esfera pública negra quando revelou o seu entusiasmo com o anticomunismo, ganhando abrigo em publicações que denunciavam o Movimento pelo Direitos Civis como um elemento subversivo da ordem social estadunidense.

A geração posterior de negros conservadores emergiu em um período em que se afirmava a perda da importância da raça como elemento estruturador das desigualdades sociais. Nesse sentido, segundo a perspectiva conservadora, o ativismo negro já havia atingido o seu objetivo, varrendo a segregação racial das instituições. $\mathrm{O}$ discurso comum, principalmente nas falas do presidente Ronald Reagan, era de que a sociedade estadunidense já estava aberta para a mobilidade social da população negra, faltava apenas aos negros assumirem a livre iniciativa. Nesse contexto, sem o espectro do racismo violento do sul, a interpretação dos conservadores negros era de que os negros deveriam assumir valores como o do trabalho duro para enfim almejarem o Sonho Americano. Nesse sentido, o grupo, diminuto e sem raízes entre a população negra, acompanhou o projeto dos republicanos de restringirem a cobertura do Welfare State, considerado-o um conjunto de programa e políticas que desencorajavam o individualismo dos negros.

A luta dos negros conservadores no período pós-direitos civis já não era mais contra o racismo, a partir de "transformações moderadas e graduais", mas a favor da "americanização" da população negra. De acordo com Sherry Smith (2002), intelectuais conservadores como Shelby Steel iniciaram o debate sobre o problema da tradição de organização coletiva dos negros, a crença de que a população negra tem um destino comum. Era necessário desrracializar os cidadãos negros e transformá-los em indivíduos. A identidade negra, portanto, aparece nos discursos dos conservadores negros como uma armadilha para a população, já que encarcera os negros em um universo coletivo, privando-os de contato com o resto da sociedade. A cultura afro-estadunidense se revela como uma barreira que distorce a percepção dos indivíduos negros 
sobre as relações sociais, que atribuem exageradamente poder à categoria de raça e abrem mão de experimentar plenamente a individualidade.

Ao fazerem o clamor pela transcendência da raça, os negros conservadores se colocam como aqueles com maior capacidade para tratar de assuntos cruciais das comunidades afroestadunidenses. Entre as questões mais debatidas estão os comportamentos imorais e violentos dos negros, que supostamente não são abordados de maneira adequada pelos intelectuais progressistas. Assim, caberia aos conservadores o papel de criticar uma "cultura da criminalidade" entre a população negra, principalmente entre os jovens que celebram os elementos da cultura Hip-Hop. Na perspectiva dos conservadores negros, grande parte dos problemas que assolam os afro-estadunidenses não estão relacionados a uma hierarquia racial construída historicamente, mas a problemas morais reproduzidos culturalmente. O Rap, por exemplo, é o fenômeno cultural que revela de melhor maneira o niilismo dos jovens negros, que veneram práticas autodestrutivas como a prostituição e a venda de drogas. Para figuras como Glenn Loury, é necessário difundir discursos de amor-próprio que enfatizem a família patriarcal, a educação e a vida profissional, reforçando uma política da respeitabilidade que estimule, sobretudo, a reconstrução de uma masculinidade "americanizada" para os indivíduos negros (MOCOMBE, 2010).

Outro aspecto importante do discurso da geração contemporânea de conservadores negros é o da capacidade da sociedade estadunidense de incluir as minorias étnicas e raciais. No esforço para comprovar o declínio da raça no país, acadêmicos como Thomas Sowell analisaram a partir de pesquisas empíricas a mobilidade social de diversos grupos étnicos. O economista, em Ethnic America (1981), por exemplo, examina a trajetória de poloneses, irlandeses, caribenhos, japoneses, entre outras comunidades. A tese de Sowell é a de que valores cultivados no país de origem são fundamentais na integração e mobilidade social de minorias étnicas. A experiência empreendedora, nesse sentido, é um elemento importante para a integração, assim como a capacidade de planejar a trajetória educacional. O economista identifica transformações profundas na década de 1970 na sociedade estadunidense que possibilitaram a inclusão de vários grupos, inclusive os negros. A experiência dos imigrantes negros caribenhos é explorada por 
Sowell, que demonstra como o grupo, por conta de diferentes origens, consegue prosperar muito mais que os afro-estadunidenses.

\begin{abstract}
Os imigrantes caribenhos não tinham uma experiência com o trabalho agrícola, no entanto, tinham uma trajetória predominantemente urbana. As diferenças entre os negros do Caribe e os dos Estados Unidos não são necessariamente profissionais. Os caribenhos trabalham muito mais e são muito mais empreendedores do que os afroamericanos. As suas crianças estudam mais e têm performance superior às crianças negras nativas. Os caribenhos nos Estados Unidos têm taxas de fertilidade e criminalidade menor que negros e brancos do país. Já em 1901, caribenhos eram proprietários de 20 por cento dos empreendimentos de Manhattan, ainda que fossem apenas 10 por cento da população negra. Os afro-americanos os chamavam de judeus negros.

(SOWELL, 1981, p. 219)
\end{abstract}

Esse processo levou Sowell a questionar as políticas de ações afirmativas, que, segundo ele, subvertiam uma ordem liberal. O intelectual conservador, em escritos posteriores, criticaria sistematicamente as iniciativas coletivas dos negros, já que considerava não haver mais nos Estados Unidos uma hierarquia racial. Para Sowell, os intelectuais progressistas haviam desenvolvido um diagnóstico errôneo da situação da população negra, apontando soluções equivocadas para confrontar as desigualdades sociais. Por outro lado, Rhonda Williams (2002) identifica falhas na metodologia das pesquisas de Sowell, que muitas vezes ignora as categorias de raça e gênero na análise do mercado de trabalho no país. $\mathrm{O}$ economista, assim como outros intelectuais conservadores, acredita no caráter inclusivo da economia estadunidense, o problema da população negra não é a raça, mas um déficit educacional histórico que compromete a trajetória dos professionais negros. Assim, uma vez livres da armadilha do pertencimento racial, os afro-estadunidenses poderão perseguir o Sonho Americano.

A aposta de conservadores negros e brancos no período pós-direitos civis foi no discurso de ascensão de uma era pós-racial. Nesse sentido, a estratégia desde a década de 1980 é a de despolitizar as agendas do movimento negro. Uma vez que supostamente a raça passa a perder a capacidade de influenciar as desigualdades sociais, os conservadores negros começaram a investir mais em assuntos morais, ressaltando a capacidade limitada dos negros de compreenderem os valores "americanos". Assim, iniciaram um ataque aos progressistas do Partido Democrata, que estariam demagogicamente estimulando o racialismo para garantir um 
eleitorado cativo nas eleições, principalmente as presidenciais. No caso de Thomas Sowell, que utiliza seu amplo conhecimento em economia, é possível observar uma análise da sociedade estadunidense que reforça os problemas educacionais das comunidades negras sem levar em consideração como a raça se manifesta nas instituições. O economista, entretanto, não deixa de tratar de aspectos culturais, principalmente ao reforçar que não existe uma cultura negra nos Estados Unidos. Na obra Black Rednecks and White Liberals, Sowell retoma as ideias de George Schuyler, afirmando a inserção dos negros na cultura estadunidense. O seu argumento é o de que a subalternidade dos negros não é determinada por uma hierarquia racial, mas uma cultura sulista que afeta negros e brancos. A dificuldade de assimilar o "trabalho duro" como valor não é um problema específico dos negros, mas de todos cidadãos imersos nessa cultura que manifesta o apreço pela criminalidade e tem origem nas classes populares brancas que historicamente se formaram no Sul do país.

\footnotetext{
De fato, diferenças culturais têm impacto econômico e social muito grande. Apesar da tendência de se atribuir as diferenças entre negros e brancos ao legado da escravidão, os negros do caribe passaram pela mesma experiência de escravização, mas trouxeram com eles elementos culturais distintos dos afro-americanos que influenciaram nos índices de empreendedorismo, educação e encarceramento. Em suma, o que os dois grupos compartilham é uma história de escravidão, o que não compartilham é uma cultura caipira do Sul.

(SOWELL, 2005, p. 62)
}

Ao questionarem a existência do racismo nos Estados Unidos, os conservadores negros contemporâneos revelam a dificuldade para se conectarem com as classes populares negras, porém garantem um espaço no campo conservador. A era "pós-racial" anunciada por conservadores e alguns setores progressistas no país possibilitou a circulação cada vez mais ampla das ideias defendidas pelos conservadores negros, principalmente as que refutam o legado da escravidão e da segregação na estrutura social estadunidense. A retórica de diminuição do Estado, muito forte entre republicanos desde a ascensão do presidente de Ronald Reagan, foi reforçada por negros conservadores que atribuíam a decadência moral dos negros à dependência de políticas públicas desde o New Deal. Dessa forma, o desmonte do anêmico Welfare State estadunidense foi tratado por conservadores como um processo pedagógico para a população 
negra, que a despertaria do sono propiciado pelos programas sociais e a estimularia a dar os primeiros passos para incorporar um "ethos americano".

\section{Considerações finais}

A linhagem conservadora negra pode ser traçada desde o século XIX a partir de agendas que enfatizavam a moderação diante de práticas racistas, as iniciativas individuais e a celebração da singularidade da nação estadunidense. Entretanto, ao longo da história, é possível identificar mudanças nas abordagens de intelectuais e lideranças negras conservadoras associadas às circunstâncias políticas. A acomodação enfatizada por Booker T. Washington diante do segregacionismo perdeu sentido com a ascensão do Movimento pelos Direitos Civis. A década de 1960 foi marcada pela emergência de forças progressistas no sul a partir de um ativismo popular que reduziu acentuadamente a circulação da filosofia da acomodação bookertiana. Por outro lado, no extremo oposto do espectro político, os conservadores se articulavam e ganhavam cada vez mais espaço no Partido Republicano, que redefiniria a sua identidade ideológica na década seguinte. Os conservadores negros deixaram as redes políticas do ativismo afroestadunidense para atuarem no campo conservador que começou a sua estruturação na década de 1950.

George Schuyler, em sua trajetória como intelectual conservador, experimentou essas mudanças na cultura política estadunidense, ascendendo profissionalmente no jornalismo negro e se aposentando com a contribuição em publicações conservadoras. Schuyler reproduziu o acomodacionismo de Booker T. Washington e celebrou o individualismo como traço essencial da identidade nacional, antecipando elementos que seriam explorados posteriormente por conservadores como Glenn Loury, Walter Williams e Thomas Sowell. Em um contexto pósdireitos civis, os conservadores negros, para afirmarem a importância da livre iniciativa e do empreendedorismo, procuraram demonstrar a ineficiência da identidade negra e, consequentemente, da categoria raça em uma ordem social supostamente livre do legado escravocrata e segregacionista. $\mathrm{O}$ que define a sociedade estadunidense, na perspectiva dos conservadores, não é a supremacia racial, mas a sua capacidade econômica de incorporar as minorias que foram incluídas ao longo da história do país. 
Os conflitos raciais que se acentuaram durante a presidência de Barack Obama trouxeram novos desafios para a intelectualidade negra conservadora. Ainda que continuem a apostar no declínio da raça, é possível perceber que muitos entusiastas da era pós-racial passaram a problematizar a ascensão de novos grupos engajados em agendas supremacistas. No caso de Ben Carson, que assumiu a Secretaria de Habitação da administração de Donald Trump, a posição é a de ignorar a presença de supremacistas que rodeiam o presidente ou de considerar a articulação de brancos supremacistas apenas como uma anomalia social que está longe de definir a estrutura social estadunidense.

\section{Referências Bibliográficas}

BRACEY, Christhoper A. Saviours or Sellouts: the promise and peril of Black conservatism, from Booker T. Washington to Condoleeza Rice. Boston: Beacon Press, 2008.

CAPELATO, Maria Helena; PRADO, Maria Lígia. O bravo matutino: imprensa e ideologia no jornal "O Estado de São Paulo”. São Paulo: Alfa Omega, 1980.

EISENSTADT, Peter (org.). Black Conservatism: Essays in Intellectual and Political History. New York: Routledge, 2012.

FRANCISCO, Flávio Thales Ribeiro. O novo negro na diáspora: modernidade afro-americana e as representações sobre o Brasil e a França no jornal Chicago Defender (1916-1940). São Paulo: Intermeios/FAPESP, 2016.

DUNN, Charles; WOODWARD, David J. The conservative tradition in America. Lanham: Rowman \& Littlefield Publishers, 1996.

GERSTLE, Gary; FRASER, Steve (org.). The rise and fall of New Deal order (1930-1980). Princeton: Princeton University Press, 1989.

GIFFORD, Laura Jane. The Center Cannot Hold: The 1960 Presidential Election and the Rise of Modern Conservatism. Northern Illinois University Press, 2009.

HELLWIG, David J. (org.). African-American reflections on Brazil's racial paradise. Philadelphia: Temple University Press, 1992. 
KIRK, Russel. The conservative mind: from Burke to Eliot. Washington DC: Regnery Publishing, 2001.

LEAK, Jeffrey B. (org.). Rac[e]ing to the right: selected essays of George S. Schuyler. Knoxville: The University of Tennessee Press, 2001.

LIMONCIC, Flavio. Os inventores do New Deal: Estado e sindicatos no combate à Grande Depressão. Rio de Janeiro: Civilização Brasileira, 2009.

MARTINS, Ana Luiza; LUCA, Tânia Regina de. História da imprensa no Brasil. São Paulo: Contexto, 2008.

McPHERSON, James Brian. The conservative resurgence and the press: the media's role in the rise of the right. Evanston: Northwestern University Press, 2008.

MILLER, Kelly. Radicals \& Conservatives and others essays on the Negro in America. New York: Schoken Books, 1968.

MOCOMBE, Paul C. The Liberal Black Protestant Heterosexual Bourgeois Male: From W.E.B. DuBois to Barack Obama. New York. United Press of America, 2010.

NASH, George. The conservative intellectual movement in America since 1945. Wilmington, Delaware: Intercollegiate Studies Institute, 2006.

SHAW-THORNBURG, Angela. Reading and writing African American travel narrative. Tese de Doutorado, Rutgers, State University of New Jersey, 2006.

SCHNEIDER, Gregory L. The conservative century: from reaction to revolution. Lanham: Rowman \& Littlefield Publishers, 2009

SCHUYLER, George S. Black and Conservative: the autobiography of George Schuyler. New Rochelle: Arlington House Publishers, 1966.

SMITH, Sherry. The individual ethos: a defining characteristic of contemporary Black conservatism. In: TATE, Gale; RANDOLPH, Lewis (org.). Dimensions of Black conservatism in the United States. New York: Palgrave, 2002.

SMITH, Virginia Whatley. "African American travel literature". In: BENDIXEN, Alfred; HAMERA, Judith (ed.). The Cambridge companion to American travel literature. Cambridge: Cambridge University Press, 2009, p. 119-139. 
SOUSA, Rodrigo Farias de. William Buckley Jr, National Review e a crítica conservadora ao liberalismo e os direitos civis nos EUA, 1955-1968. Tese de Doutorado, Universidade Federal Fluminense, 2013.

SOWELL, Thomas. Black Rednecks and White liberals. San Francisco: Encounter Books, 2005 Ethnic America: a History. New York: Basic Books, 1981.

SUGGS, Henry Lewis. P.B. Young, Newspaperman: Race, Politics and Journalism in the New South, 1910-1962. Charlottesville, Va.: University Press of Virginia, 1988.

XAVIER, Giovana. Brancas de Almas Negras? Beleza, racialização e cosmética na imprensa negra pós-emancipação (EUA, 1890-1930). Tese de Doutorado, Universidade Estadual de Campinas, 2012.

WALKER, Lee H. Rediscovering Black conservatism. Chicago: The Heartland Institute, 2009. WASHINGTON, Booker T. Up from slavery. Nova York: Dover Publications, 1995.

WATSON, Shelly L. The Pittsburg Courier: advocate for integration of the U.S. Armed Forces (1934-1940). Dissertação de Mestrado, San Jose State University, 2013.

WILLIAMS, Harry M. When Black is right: the life and writings of George S. Schuyler. Tese de Doutorado, Brown University, 1988.

WILLIAMS, Oscar R. George S. Schuyler: portrait of a black conservative. Knoxville: University of Tennessee Press, 2007.

WILLIAMS, Rhonda. "If it ain't broken, don't fox it": Thomas Sowell on Black Women, affirmative action, and the death of discrimination. In: TATE, Gale; RANDOLPH, Lewis (org.). Dimensions of Black conservatism in the United States. New York: Palgrave, 2002, p. 85-100. WRIGHT, Leah Michele. The loneliness of Black conservatives: Black republicans and the Grand Old Party, 1964-1980. Tese de Doutorado, Princeton University, 2009. 